\title{
Apoptotic effect of hot water extract of Sanguisorba officinalis L. in human oral cancer cells
}

\author{
JI-AE SHIN $^{1 *}$, JUN-SUNG KIM $^{2 *}$, KI-HAN KWON ${ }^{3}$, JEONG-SEOK NAM $^{4}$, \\ $\mathrm{JI}_{-} \mathrm{YOUN}_{\mathrm{JUNG}}{ }^{5}$, NAM-PYO $\mathrm{CHO}^{1}$ and SUNG-DAE CHO ${ }^{1}$
${ }^{1}$ Department of Oral Pathology, School of Dentistry, Institute of Oral Bioscience, Chonbuk National University, Jeonju;
${ }^{2}$ R\&D Center, Biterials Co. Ltd., Seoul; ${ }^{3}$ Department of Food Science and Nutrition,
College of Health Welfare and Education, Gwangju University, Gwangju;
${ }^{4}$ Lee Gil Ya Cancer and Diabetes Institute, Gachon University of Medicine and Science, Inchon;
${ }^{5}$ Department of Companion and Laboratory Animal Science, Kongju National University, Yesan, Republic of Korea

Received February 22, 2012; Accepted June 1, 2012

DOI: $10.3892 / \mathrm{ol} .2012 .748$

\begin{abstract}
Sanguisorba officinalis L. has been used in traditional Asian medicine to treat diseases including diarrhea, chronic intestinal infections, duodenal ulcers and bleeding. This study examined the antiproliferative effects and apoptotic activity of hot water extract of $S$. officinalis L. (HESO) on HSC4 and HN22 human oral cancer cells. The effects of HESO were evaluated by the 3-(4,5-dimethylthiazol-20yl)(3-carboxymethoxyphenyl)-2-(4-sulphophenyl)-2H-tetrazolium (MTS) assay, 4'-6-diamidino-2-phenylindole (DAPI) staining and western blot analysis. HESO was found to inhibit cell growth and induce apoptosis in HSC4 and HN22 oral cancer cells. HESO downregulated myeloid cell leukemia-1 (Mcl-1) in HSC4 cells and was associated with the activation of Bak, resulting in Bak oligomerization on the mitochondrial outer membrane. HESO did not alter Mcl-1 expression in HN22 cells, but it decreased Sp1 expression. The downregulation of Sp1 by HESO in HN22 cells resulted in a decrease in survivin, a downstream target protein of Sp1. These results suggested that HESO inhibited the growth of oral cancer through either Mcl-1 or Sp1, indicating that HESO may serve as a potential drug candidate against oral cancer.
\end{abstract}

\section{Introduction}

Statistical projections indicated that $1,596,670$ new cases of cancer and 571,950 mortalities would occur in the United

Correspondence to: Professor Sung-Dae Cho, Department of Oral Pathology, School of Dentistry, Institute of Oral Bioscience, Chonbuk National University, Jeonju 561-756, Republic of Korea E-mail: efiwdsc@chonbuk.ac.kr

*Contributed equally

Key words: Sanguisorba officinalis L., myeloid cell leukemia-1, specificity protein 1 , oral cancer, apoptosis
States in 2011 (1). Oral cancer is a serious health problem in many other parts of the world and the eighth-leading cause of cancer-related death in men. Certain studies suggest that the risk factors for oral cancer are tobacco, alcohol, ultraviolet light and oral lesions $(2,3)$. Although the incidence of oral cancer is low, patients have a poor prognosis, and the five-year survival rate has remained unchanged at approximately $50 \%$. Accordingly, the development of more effective therapeutic strategies for the prevention and therapy of oral cancer is imperative.

Mcl-1 is a Bcl-2-family protein that is essential in apoptosis control, and it rapidly decreases during apoptosis (4). In human malignancies, the increased expression of Mcl-1 causes tumor progression and chemoresistance (5). Natural products derived from plant sources modulate apoptosis through the downregulation of Mcl-1. Lycorine isolated from Amaryllidaceae lycoris induces apoptosis and causes a rapid turnover of Mcl-1 expression in human leukemia cell lines (6). The apoptotic effects of Honokiol, purified from magnolia, appear to be associated with the downregulation of Mcl-1 in B-cell chronic lymphocytic leukemia (7). Thus, the downregulation of Mcl-1 may be an attractive therapeutic strategy for inducing apoptosis. The pro-apoptotic protein Bak is constitutively integrated in the mitochondrial outer membrane, but changes conformation and forms oligomeric complexes in response to apoptotic stimuli (8). Notably, the downregulation of Mcl-1 by chemotherapeutic agents is associated with the activation of Bak (9-11). Therefore, the study of Bak in cancer cells expressing Mcl-1 may provide a promising strategy.

Sanguisorba officinalis L. has anti-inflammatory, antiallergic and anxiolytic activities (12-15). Moreover, several triterpenoids isolated from the roots of $S$. officinalis L. have been shown to inhibit the growth of tumor cell lines (16). However, its effects in oral cancer and the mechanism of S. officinalis L.-induced apoptosis remain poorly defined. In this study, we provide experimental evidence that an extract of S. officinalis L. inhibits cell growth and induces apoptosis in oral cancer cell lines. 

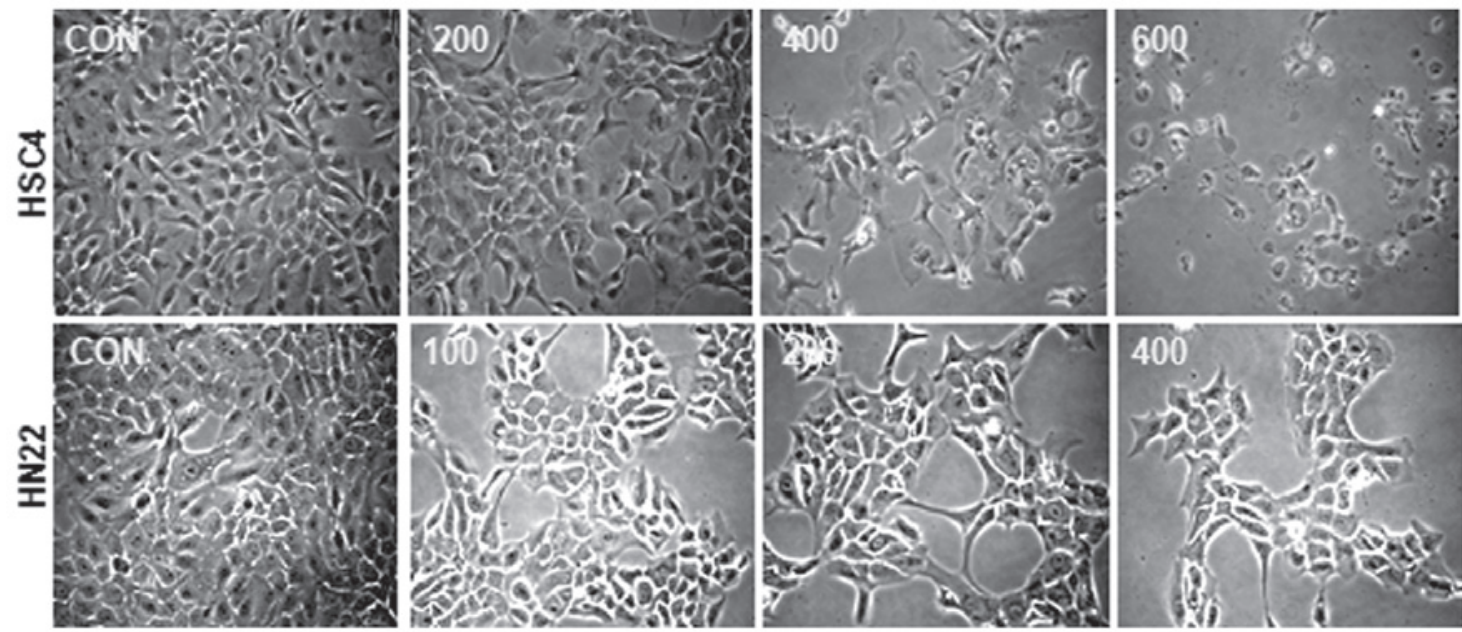

Figure 1. The effect of HESO on morphology of HSC4 and HN22 cells. Cells were treated with vehicle (DMSO) or various doses of HESO (200, 400 and $600 \mu \mathrm{g} / \mathrm{ml}$ for HSC4 cells and 100, 200 and $400 \mu \mathrm{g} / \mathrm{ml}$ for HN22 cells) for $48 \mathrm{~h}$. Cell viability was determined by photographs captured by optical microscope after $48 \mathrm{~h}$. Magnification, x200. HESO, hot water extract of Sanguisorba officinalis L.

\section{Materials and methods}

Reagents. Hot water extract of S. officinalis L. (HESO) was kindly provided by Professor Ki-Han Kwon (Kwangju University, Kwangju, Korea). PARP antibody was obtained from BD Pharmingen (San Jose, CA, USA). Sp1 and actin antibodies were obtained from Santa Cruz Biotechnology, Inc. (Santa Cruz, CA, USA). Antibodies against Mcl-1, Bak and survivin were obtained from Cell Signaling Technology, Inc. (Charlottesville, VA, USA).

Cell culture and chemical treatment. HSC 4 cells were provided by Hokkaido University (Hokkaido, Japan) and HN22 cells were provided by Dankook University (Cheonan, Korea). Both cells were cultured in Dulbecco's modified Eagle's medium (DMEM) supplemented with $10 \%$ fetal bovine serum (FBS) and antibiotics at $37^{\circ} \mathrm{C}$ in a $5 \% \mathrm{CO}_{2}$ incubator. Cells were treated with vehicle (DMSO) or HESO (200, 400 and $600 \mu \mathrm{g} / \mathrm{ml}$ for HSC4 cells and 100, 200 and $400 \mu \mathrm{g} / \mathrm{ml}$ for HN22 cells) for $48 \mathrm{~h}$.

MTS assay. The effect of HESO on cell viability was tested using the CellTiter 96 Aqueous One Solution Cell Proliferation Assay kit (Promega, Madison, WI, USA) according to the manufacturer's instructions for 3-(4,5-dimethylthiazol-20yl)(3-carboxymethoxyphenyl)-2- (4-sulphophenyl)-2H-tetrazolium (MTS) assay. Briefly, cells were seeded in 96-well plates and incubated for different times with different doses of HESO. The absorbance was measured at 490 and $690 \mathrm{~nm}$ (background) using an ELISA microplate reader (BioTek Instruments, Inc., Madison, WI, USA). The data were expressed as the percentage of cell viability compared to the control.

DAPI staining. Apoptotic cells with chromatin condensation and nuclear fragmentation were confirmed morphologically using fluorescent nuclear dye 4'-6-diamidino-2-phenylindole (DAPI; Sigma Chemical Co, MO, USA). HSC4 and HN22 cells treated with HESO were harvested by trypsinization and fixed in $100 \%$ methanol at room temperature for $10 \mathrm{~min}$. Both cells were deposited on slides and stained with DAPI solution
( $2 \mu \mathrm{g} / \mathrm{ml})$. The cell morphology was observed under a fluorescence microscope.

Western blot analysis. Whole cell lysates were extracted using lysis buffer and the protein concentration of lysates was quantified using the DC Protein Assay (Bio-Rad Laboratories, Hercules, CA, USA). Samples containing equal amounts of protein were separated by SDS-PAGE and transferred to Immun-Blot PVDF membranes (Bio-Rad). The membranes were blocked with 5\% skimmed milk in TBST at room temperature for $2 \mathrm{~h}$, and incubated overnight at $4^{\circ} \mathrm{C}$ with primary antibodies against PARP, Sp1, Mcl-1, Bak, survivin or actin, followed by incubation with HRP-conjugated secondary antibodies. Antibody-bound proteins were detected using the ECL Western Blotting Luminol reagent (Santa Cruz Biotechnology, Inc.).

Detection of Bak activation. HSC4 cells were harvested and whole-cell lysates were extracted using lysis buffer. The extracted protein was analyzed by western blot analysis. Bak activation was detected using the primary antibody recognizing only the active form of Bak (Ab-2).

Cross-linking. For Bak oligomerization, HSC4 cells were treated with vehicle (DMSO) or HESO (200, 400 and $600 \mu \mathrm{g} / \mathrm{ml}$ ) for $48 \mathrm{~h}$. Cells were harvested and suspended in conjugation buffer with $10 \mathrm{mM}$ EDTA. Lysates were incubated with $0.2 \mathrm{mM}$ bismaleimide (BMH; Thermo Scientific, Rockford, IL, USA) at room temperature for $1 \mathrm{~h}$, and then extracted with lysis buffer for western blot analysis.

Statistical analysis. Student's t-test was used to determine the significance of differences between the control and treatment groups, and $\mathrm{p}<0.05$ was considered to indicate a statistically significant result.

\section{Results}

Growth inhibition effects of HESO on human oral cancer cells. To investigate whether HESO inhibits the growth of HSC4 and 
A

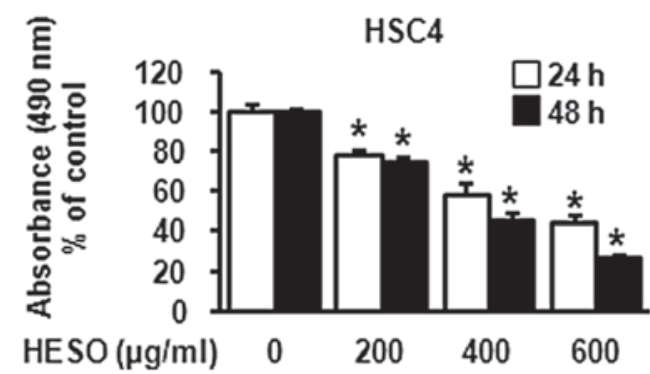

B

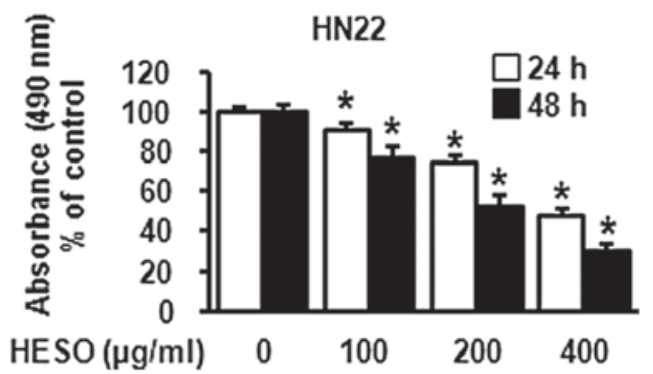

Figure 2. The effect of HESO on viability of (A) HSC4 and (B) HN22 cells. Cells were treated with vehicle (DMSO) or various doses of HESO (200, 400 and $600 \mu \mathrm{g} / \mathrm{ml}$ for HSC4 cells and 100, 200 and $400 \mu \mathrm{g} / \mathrm{ml}$ for HN22 cells) for 24 or $48 \mathrm{~h}$. The effect of HESO cell viability was determined using an MTS assay. Graphs are the mean with standard deviations of three independent experiments. "p $<0.05$ compared with DMSO-treated group. HESO, hot water extract of Sanguisorba officinalis L.

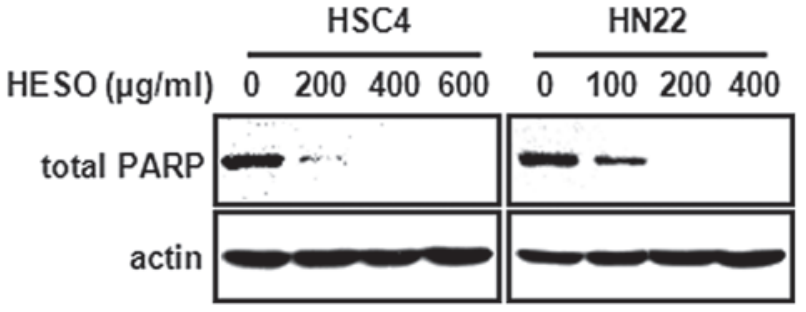

Figure 3. Apoptotic effect of HESO on total PARP by western blot analysis. Total PARP was determined as an apoptotic marker protein, and actin was used as a loading control. HESO, hot water extract of Sanguisorba officinalis L.

HN22 human oral cancer cells, cells were treated with DMSO or various doses of HESO $(200,400$ and $600 \mu \mathrm{g} / \mathrm{ml}$ for HSC4 cells and 100, 200 and $400 \mu \mathrm{g} / \mathrm{ml}$ for HN22 cells) for 24 or $48 \mathrm{~h}$. The morphological changes were observed using an optical microscope after $48 \mathrm{~h}$. Results showed that HESO-treated cells were detached in a dose-dependent manner (Fig. 1). The effect of HESO on cell viability was examined using the MTS assay. The cell viability of both cell lines decreased signficantly and dose-dependently upon treatment with HESO (Fig. 2A and B). The IC50 value was $391.3 \mu \mathrm{g} / \mathrm{ml}$ for HSC4 cells and
$259.9 \mu \mathrm{g} / \mathrm{ml}$ for HN22 cells at $48 \mathrm{~h}$. These results indicated that HESO inhibited growth of human oral cancer cells.

Apoptotic effect of HESO on human oral cancer cells. We then examined whether the growth inhibition by HESO was associated with an apoptotic effect using western blot analysis and DAPI staining. Fig. 3 demonstrates that there was a decrease in total PARP expression in both cells lines following treatment with HESO for $48 \mathrm{~h}$, indicating that PARP might be cleaved to yield a $89-\mathrm{kDa}$ fragment. In addition, HSC4 and HN22 cells treated with various doses of HESO for $48 \mathrm{~h}$ exhibited chromatin condensation and nuclear fragmentation, characteristic features of cells undergoing apoptosis. The percentage of cells with nuclear fragmentation in the HESO-treated group compared with the DMSO-treated group is shown in Fig. 4A and $\mathrm{B}$. These results demonstrate that HESO induced apoptosis in human oral cancer cells.

HESO induces downregulation of either Mcl-1 or Sp1. An earlier study suggest that downregulation of Mcl-1 protein may be required to initiate the apoptosis cascade leading to cytochrome c release (17). Our own previous study found that the inhibition of Mcl-1 by tolfenamic acid induces apoptosis
$\mathbf{A}$
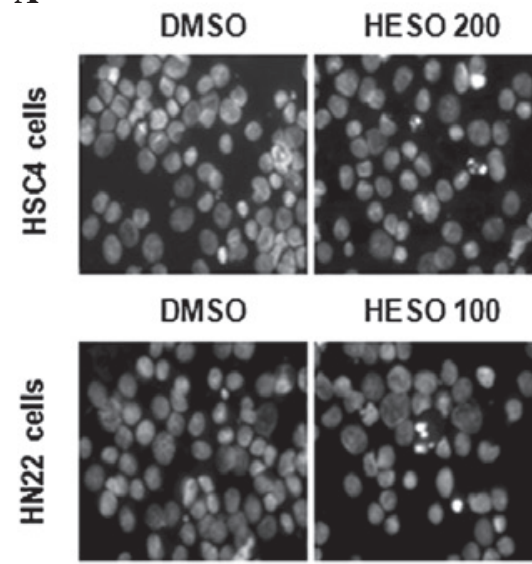

HESO 100

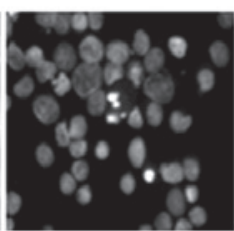

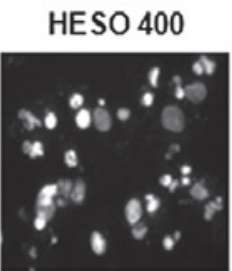

HESO 200

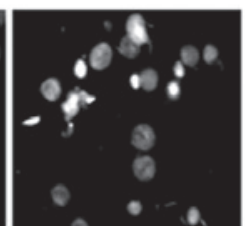

HESO 600

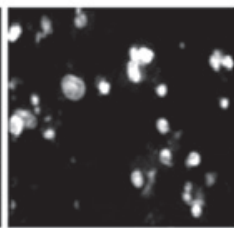

HESO 400

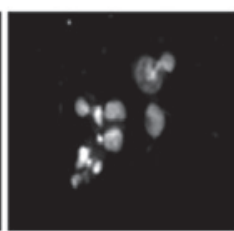

B

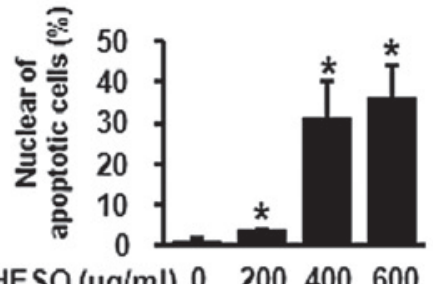

HESO $(\mu \mathrm{g} / \mathrm{ml}) 0 \quad 200400600$

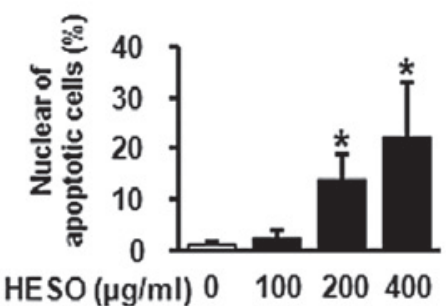

Figure 4. Apoptotic effect of HESO by DAPI staining. (A) Chromatin condensation and nuclear fragmentation were detected by fluorescence microscopy (magnification, x400). (B) DAPI-stained cells were quantified and apoptotic cell numbers are shown as means with standard deviation. ${ }^{*} \mathrm{p}<0.05$ compared with DMSO-treated group. HESO, hot water extract of Sanguisorba officinalis L. 
A

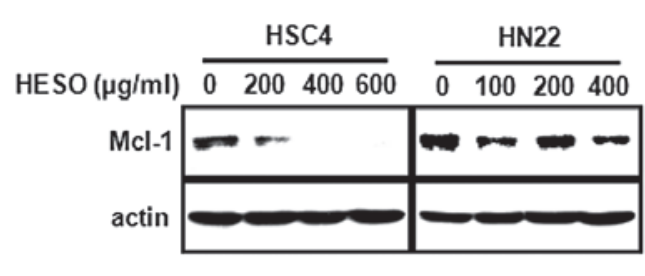

C

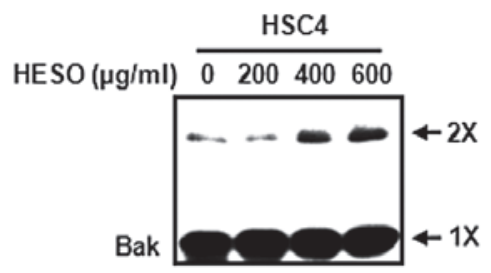

B

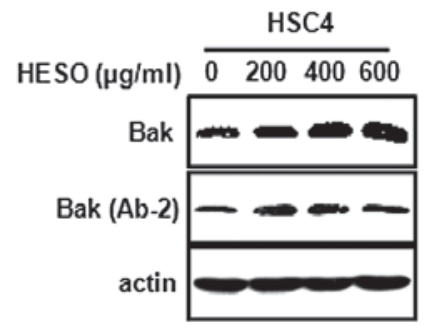

D

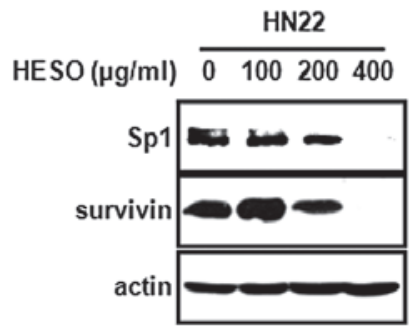

Figure 5. (A) The protein level of Mcl-1 was evaluated by western blot analysis in HSC4 and HN22 cells treated with HESO. (B) Total Bak and active Bak (Ab-2) in HSC4 cells were evaluated by western blot analysis. (C) For detection of Bak oligomerization, cell lysates were treated with $0.2 \mathrm{mM}$ bismaleimide, and analyzed using western blot analysis with anti-Bak (2X represents Bak complexes with dimer; $1 \mathrm{X}$ represents inactive Bak conformer). (D) Protein levels of Sp1 and survivin in HN2 cells were evaluated by western blot analysis.

in mucoepidermoid carcinoma (18). Thus, we investigated whether HESO affects Mcl-1 expression in HSC4 and HN22 oral cancer cells. Fig. 5A shows that HESO decreased Mcl-1 expression in HSC4 cells but had no significant effect on Mcl-1 in HN22 cells. To further investigate whether the downregulation of Mcl-1 by HESO in HSC4 cells affects the downstream targets Bak and Bax, HSC4 cells were treated with various doses of HESO, and Bak and Bax protein levels were measured. Fig. 5B shows that HESO caused a marked increase in Bak expression, but failed to modulate Bax expression. During the apoptotic cell death process, Bak undergoes a conformational change and oligomerization on the mitochondrial outer membrane. To evaluate whether Bak underwent a conformational change from the inactive form to the active form during HESO-induced apoptosis, we measured Bak using an antibody recognizing only the active form. The results demonstrated that HESO treatment resulted in an increase in the active form of Bak, indicating that Bak underwent a conformational change. We next investigated whether the Bak protein oligomerized on the mitochondrial outer membrane. Following treatment of HSC4 cells with HESO, BMH was used to crosslink oligomerized Bak. Fig. 5C shows that the level of oligomerized Bak increased in HESO-treated HSC4 cells. Next, we investigated whether HESO affected Sp1 in HN22 cells, since HESO did not change Mcl-1 protein expression. HESO was found to significantly decrease $\mathrm{Sp1}$ and also reduce the expression of survivin, its downstream target (Fig. 5D).

\section{Discussion}

The evasion of apoptosis is associated with tumor progression, chemotherapy resistance and poor clinical outcome. Cancer cells escape from apoptosis by increasing the expression of anti-apoptotic proteins, including $\mathrm{Bcl}-2, \mathrm{Bcl}-\mathrm{xl}, \mathrm{Mcl}-1$ and Bfl-1/A1 (19). In particular, Mcl-1 is relatively highly expressed in malignant cell types, suggesting that Mcl-1 is associated with the evasion of apoptosis. Recently, several groups have suggested that downregulation of Mcl-1 enhances apoptosis in diverse cancer cells. Targeting Mcl-1 by small interfering RNA markedly decreases its expression in resistant melanoma cells and sensitizes them to Fas-induced apoptosis (20). The use of cyclin-dependent kinase (CDK) inhibitors, including flavopiridol and roscovitine derivative seliciclib, potentiates Mcl-1 downregulation to induce apoptosis (21-23). Moreover, the mitogen-activated protein kinase kinase 1 inhibitor PD98059 and Raf inhibitor BAY43-9006 (sorafenib) synergistically enhance apoptosis induced by the Bcl-2/Bcl-xL inhibitor ABT-737 by downregulating Mcl-1 expression $(5,24,25)$. These findings suggest that downregulation of Mcl-1 is essential for the regulation of apoptotic cell death.

In this study, we determined whether HESO was capable of inhibiting cell growth and decreasing Mcl-1 expression to induce apoptosis in oral cancer cells. We found that HESO inhibited cell growth and induced apoptosis in HSC4 and HN22 oral cancer cell lines. However, HESO-induced apoptosis in HSC4 cells was associated with a decrease in Mcl-1 expression, whereas Mcl-1 expression did not change in HN22 cells.

Permeabilization of the mitochondria during apoptosis is regulated by pro-apoptotic proteins, including multidomain Bak and Bax, and BH3-only; Bim and tBid, which are activators of Bax/Bak; and Bad, Bik, Noxa, Puma, Hrk and Bmf, which are sensitizers of $\mathrm{Bax} / \mathrm{Bak}$. These interplay with anti-apoptotic proteins, including Bcl-2, Bcl-xl, Mcl-1 and Bfl-1/A1. Upon the induction of apoptosis, several apoptogenic factors (including cytochrome $\mathrm{c}$ and AIF) are released from the mitochondria to the cytosol $(26,27)$. AIF is involved in initiating a caspaseindependent pathway of apoptosis, while cytochrome $\mathrm{c}$ binds to Apaf-1 and caspase 9, leading to complex formation and the activation of caspases such as caspase 3 and caspase 7 (28). Recent studies suggest that Bak activation is required for cytochrome $\mathrm{c}$ to be released and for apoptosis to occur (29-32). This process is followed by the induction of a conformational 
change and oligomerization of Bak in the mitochondrial outer membrane in response to multiple death signals $(33,34)$. Thus, we investigated whether Bak underwent a conformational change and whether oligomerization occurred on the mitochondrial outer membrane when HESO induced apoptosis in HSC4 cells. We found that HESO induced the conformational change and oligomerization of Bak. These results showed that the downregulation of Mcl-1 by HESO in HSC4 cells may be associated with the modulation of Bak protein.

In view of the observation that Mcl-1 expression was not altered by HESO in HN22 cells, we hypothesized that the mechanism of HESO on apoptotic activity might be different in each cell line. Therefore, we focused on the molecular target for HESO-induced apoptosis in HN22 cells. Previous studies reported that $\mathrm{Sp} 1$ is overexpressed in many human tumor and cancer cell lines $(35,36)$. Furthermore, we reported that downregulation of $\mathrm{Sp} 1$ induces apoptosis in cervical, prostate and oral cancer cells (37-39). Thus, we examined whether HESO-induced apoptosis was associated with the Sp1 protein. We found that HESO decreased Sp1 expression in HN22 cells. Several studies found that $\mathrm{Sp} 1$ regulates survivin as its downstream target in various cancer cell lines (37,39-41). We also found that HESO significantly decreased survivin, suggesting that the downregulation of Sp1 by HESO in HN22 cells resulted in a decrease of survivin expression.

In summary, HESO decreased cell growth and induced apoptosis in HSC4 and HN22 human oral cancer cells. HESO reduced Mcl-1 protein in HSC4 cells and caused the activation and oligomerization of Bak, inducing apoptosis. In HN22 cells, HESO decreased Sp1 and its downstream target, survivin. Although a study of the antitumor effect of HESO in animal models is required, our results clearly demonstrate that HESO may be a potential drug candidate against oral cancer, targeting either Mcl-1 or Sp1.

\section{Acknowledgements}

This study was supported by the National Research Foundation of Korea (NRF) and funded by the Ministry of Education, Science and Technology (2011-0019173).

\section{References}

1. Siegel R, Ward E, Brawley O and Jemal A: Cancer statistics: the impact of eliminating socioeconomic and racial disparities on premature cancer deaths. CA Cancer J Clin 61: 212-236, 2011.

2. Mashberg A, Boffetta P, Winkelman R and Garfinkel L: Tobacco smoking, alcohol drinking, and cancer of the oral cavity and oropharynx among U.S. veterans. Cancer 72: 1369-1375, 1993.

3. Neville BW and Day TA: Oral cancer and precancerous lesions. CA Cancer J Clin 52: 195-215, 2002.

4. Michels J, Johnson PW and Packham G: Mcl-1. Int J Biochem Cell Biol 37: 267-271, 2005.

5. Liu XS, Jiang J, Jiao XY, Wu YE, Lin JH and Cai YM: Lycorine induces apoptosis and down-regulation of Mcl-1 in human leukemia cells. Cancer Lett 274: 16-24, 2009.

6. Battle TE, Arbiser J and Frank DA: The natural product honokiol induces caspase-dependent apoptosis in B-cell chronic lymphocytic leukemia (B-CLL) cells. Blood 106: 690-697, 2005

7. Lee NH, Lee, MY, Lee JA, Jung DY, Seo CS, Kim JH and Shin HK: Anti-asthmatic effect of Sanguisorba officinalis L. and potential role of heme oxygenase-1 in an ovalbumin-induced murine asthma model. Int J Mol Med 26: 201-208, 2010.

8. Van Delft MF and Huang DC: How the Bcl-2 family of proteins interact to regulate apoptosis. Cell Res 16: 203-213, 2006.
9. Dash R, Richards JE, Su ZZ, Bhutia SK, Azab B, Rahmani M, Dasmahapatra G, Yacoub A, Dent P, Dmitriev IP, et al: Mechanism by which Mcl-1 regulates cancer-specific apoptosis triggered by mda-7/IL-24, an IL-10-related cytokine. Cancer Res 70: 5034-5045, 2010 .

10. Okumura K, Huang S and Sinicrope FA: Induction of Noxa sensitizes human colorectal cancer cells expressing Mcl-1 to the small-molecule Bcl-2/Bcl-xL inhibitor, ABT-737. Clin Cancer Res 14: 8132-8142, 2008.

11. Chen S, Dai Y, Harada H, Dent P and Grant S: Mcl-1 down-regulation potentiates ABT-737 lethality by cooperatively inducing Bak activation and Bax translocation. Cancer Res 67: 782-791, 2007.

12. Lee NH, Lee, MY, Lee JA, Jung DY, Seo CS, Kim JH and Shin HK: Anti-asthmatic effect of Sanguisorba officinalis L. and potential role of heme oxygenase- 1 in an ovalbumin-induced murine asthma model. Int J Mol Med 26: 201-208, 2010.

13. Shin TY, Lee KB and Kim SH: Anti-allergic effects of Sanguisorba officinalis on animal models of allergic reactions. Immunopharmacol Immunotoxicol 24: 455-468, 2002.

14. Yu T, Lee YJ, Yang HM, Han S, Kim JH, Lee Y, Kim C, Han MH, Kim MY, Lee J and Cho JY: Inhibitory effect of Sanguisorba officinalis ethanol extract on NO and PGE production is mediated by suppression of NF-kappaB and AP-1 activation signaling cascade. J Ethnopharmacol 134: 11-17, 2011.

15. Hachiya A, Kobayashi A, Ohuchi A, Kitahara T and Takema Y: The inhibitory effect of an extract of Sanguisorba officinalis L. on ultraviolet B-induced pigmentation via the suppression of endothelin-converting enzyme-1alpha. Biol Pharm Bull 24: 688-692, 2001.

16. Liu X, Cui Y, Yu Q and Yu B: Triterpenoids from Sanguisorba officinalis. Phytochemistry 66: 1671-1679, 2005.

17. Nijhawan D, Fang M, Traer E, Zhong Q, Gao W, Du F and Wang X: Elimination of Mcl-1 is required for the initiation of apoptosis following ultraviolet irradiation. Genes Dev 17: 1475-1486, 2003

18. Choi KH, Shim JH, Huong LD, Cho NP and Cho SD: Inhibition of myeloid cell leukemia-1 by tolfenamic acid induces apoptosis in mucoepidermoid carcinoma. Oral Dis 17: 469-475, 2011.

19. Gul O, Basaga H and Kutuk O: Apoptotic blocks and chemotherapy resistance: strategies to identify Bcl-2 protein signatures. Brief Funct Genomic Proteomic 7: 27-34, 2008.

20. Chetoui N, Sylla K, Gagnon-Houde JV, Alcaide-Loridan C, Charron D, Al-Daccak R and Aoudjit F: Down-regulation of mcl-1 by small interfering RNA sensitizes resistant melanoma cells to fas-mediated apoptosis. Mol Cancer Res 6: 42-52, 2008.

21. Ma Y, Cress WD and Haura EB: Flavopiridol-induced apoptosis is mediated through up-regulation of E2F1 and repression of Mcl-1. Mol Cancer Ther 2: 73-81, 2003.

22. Gojo I, Zhang B and Fenton RG: The cyclin-dependent kinase inhibitor flavopiridol induces apoptosis in multiple myeloma cells through transcriptional repression and down-regulation of Mcl-1. Clin Cancer Res 8: 3527-3538, 2002.

23. MacCallum DE, Melville J, Frame S, Watt K, Anderson S, Gianella-Borradori A, Lane DP and Green SR: Seliciclib (CYC202, R-Roscovitine) induces cell death in multiple myeloma cells by inhibition of RNA polymerase II-dependent transcription and down-regulation of Mcl-1. Cancer Res 65: 5399-5407, 2005.

24. Konopleva M, Contractor R, Tsao T, Samudio I, Ruvolo PP, Kitada S, Deng X, Zhai D, Shi YX, Sneed T, et al: Mechanisms of apoptosis sensitivity and resistance to the $\mathrm{BH} 3$ mimetic ABT-737 in acute myeloid leukemia. Cancer Cell 10: 375-388, 2006.

25. Lin X, Morgan-Lappe S, Huang X, Li L, Zakula DM, Vernetti LA, Fesik SW and Shen Y: 'Seed' analysis of off-target siRNAs reveals an essential role of Mcl-1 in resistance to the small-molecule Bcl-2/Bcl-XL inhibitor ABT-737. Oncogene 26: 3972-3979, 2007.

26. Fulda S, Scaffidi C, Susin SA, Krammer PH, Kroemer G, Peter ME and Debatin KM: Activation of mitochondria and release of mitochondrial apoptogenic factors by betulinic acid. J Biol Chem 273: 33942-33948, 1998.

27. Li Y, He K, Huang Y, Zheng D, Gao C, Cui L and Jin YH: Betulin induces mitochondrial cytochrome $\mathrm{c}$ release associated apoptosis in human cancer cells. Mol Carcinog 49: 630-640, 2010.

28. Zong WX, Li C, Hatzivassiliou G, Lindsten T, Yu QC, Yuan J and Thompson CB: Bax and Bak can localize to the endoplasmic reticulum to initiate apoptosis. J Cell Biol 162: 59-69, 2003.

29. Germain M, Milburn J and Duronio V. MCL-1 inhibits BAX in the absence of MCL-1/BAX Interaction. J Biol Chem 283: 6384-6392, 2008. 
30. Shankar S and Srivastava RK: Bax and Bak genes are essential for maximum apoptotic response by curcumin, a polyphenolic compound and cancer chemopreventive agent derived from turmeric, Curcuma longa. Carcinogenesis 28: 1277-1286, 2007.

31. Labi V, Erlacher M, Kiessling S and Villunger A: BH3-only proteins in cell death initiation, malignant disease and anticancer therapy. Cell Death Differ 13: 1325-1338, 2006.

32. Leber B, Lin J and Andrews DW: Embedded together: the life and death consequences of interaction of the Bcl-2 family with membranes. Apoptosis 12: 897-911, 2007.

33. Upreti M, Chu R, Galitovskaya E, Smart SK and Chambers TC: Key role for Bak activation and Bak-Bax interaction in the apoptotic response to vinblastine. Mol Cancer Ther 7: 2224-2232, 2008.

34. Heath-Engel HM and Shore GC: Regulated targeting of Bax and Bak to intracellular membranes during apoptosis. Cell Death Differ 13: 1277-1280, 2006.

35. Wang L, Wei D, Huang S, Peng Z, Le X, Wu TT, Yao J, Ajani J and Xie K: Transcription factor $\mathrm{Spl}$ expression is a significant predictor of survival in human gastric cancer. Clin Cancer Res 9: 6371-6380, 2003.

36. Shi Q, Le X, Abbruzzese JL, Peng Z, Qian CN, Tang H, Xiong Q, Wang B, Li XC and Xie K: Constitutive Spl activity is essential for differential constitutive expression of vascular endothelial growth factor in human pancreatic adenocarcinoma. Cancer Res 61: 4143-4154, 2001.
37. Shim JH, Shin JA, Jung JY, Choi KH, Choi ES, Cho NP, Kong G, Ryu MH, Chae JI and Cho SD: Chemopreventive effect of tolfenamic acid on KB human cervical cancer cells and tumor xenograft by downregulating specificity protein 1. Eur J Cancer Prev 20: 102-111, 2011.

38. Choi ES, Shim JH, Jung JY, Kim HJ, Choi KH, Shin JA, Nam JS, Cho NP and Cho SD: Apoptotic effect of tolfenamic acid in androgen receptor-independent prostate cancer cell and xenograft tumor through specificity protein 1 . Cancer Sci 102: 742-748, 2011.

39. Shin JA, Shim JH, Jeon JG, Choi KH, Choi ES, Cho NP and Cho SD: Apoptotic effect of Polygonum Cuspidatum in oral cancer cells through the regulation of specificity protein 1 . Oral Dis 17: 162-170, 2011.

40. Li F and Altieri DC: Transcriptional analysis of human survivin gene expression. Biochem J 344 Pt 2: 305-311, 1999.

41. Chun JY, Hu Y, Pinder E, Wu J, Li F and Gao AC: Selenium inhibition of survivin expression by preventing Sp1 binding to its promoter. Mol Cancer Ther 6: 2572-2580, 2007. 